\title{
Pubertal outcomes and sex of rearing of patients with ovotesticular disorder of sex development and mixed gonadal dysgenesis
}

Yoon Myung Kim, $\mathrm{MD}^{1}$, Arum $\mathrm{Oh}, \mathrm{MD}^{2}$, Kun-Suk Kim, MD', Han-Wook Yoo, MD, PhD², Jin-Ho Choi, MD ${ }^{2}$

'Department of Pediatrics, GangNeung Asan Hospital, Gangneung, Korea ${ }^{2}$ Department of Pediatrics, Asan Medical Center Children's Hospital, University of Ulsan College of Medicine, Seoul, Korea

${ }^{3}$ Department of Urology, Asan Medical Center Children's Hospital, University of Ulsan College of Medicine, Seoul, Korea
Received: 20 May, 2019

Revised: 2 July, 2019

Accepted: 29 July, 2019

Address for correspondence: Jin-Ho Choi, MD

Department of Pediatrics, Asan Medical Center Children's Hospital, University of Ulsan College of Medicine, 88, Olympic-ro 43-Gil, Songpa-Gu, Seoul 05505, Korea Tel: +82-2-3010-3991

Fax: $+82-2-473-3725$

E-mail: jhc@amc.seoul.kr https://orcid.org/0000-0003-11967826
Purpose: Patients with ovotesticular disorder of sex development (DSD) and mixed gonadal dysgenesis (MGD) usually present with asymmetric gonads and have wide phenotypic variations in internal and external genitalia. The differential diagnosis of these conditions is based on karyotype and pathological findings of the gonads. This study investigated the clinical features at presentation, karyotype, sex of rearing, and pubertal outcomes of patients with ovotesticular DSD and MGD.

Methods: The study comprised 23 patients with DSD who presented with asymmetric gonads. The presenting features, karyotype, sex of rearing, and pubertal outcomes were reviewed retrospectively.

Results: All 23 patients presented with ambiguous genitalia at a median age of 1 month (range, 1 day-1.6 years). Müllerian duct remnants were identified in 15 of 23 patients (65.2\%). Fourteen patients were diagnosed with ovotesticular DSD, whereas the other 9 were diagnosed with MGD. Eight of 14 patients (57.1\%) with ovotesticular DSD were raised as males, while 7 of 9 patients with MGD $(77.8 \%)$ were assigned as males. One male-assigned patient with ovotesticular DSD changed to female sex at age 20 years.

Conclusion: Patients with ovotesticular DSD and MGD manifest overlapping clinical presentations and hormonal profiles. It is difficult to determine the sex of rearing and predict long-term pubertal outcomes. Therefore, long-term followup is required to monitor spontaneous puberty, sex outcome, and urological and gynecological complications.

Keywords: Ambiguous genitalia, Disorder of sex development, Gonadal dysgenesis, Ovotestis

\section{Introduction}

Disorders of sex development (DSD) can be classified into 46,XY DSD; 46,XX DSD; and sex chromosome DSD. ${ }^{1)}$ However, some conditions, such as ovotesticular DSD and gonadal dysgenesis, do not clearly fit into a specific diagnostic category or may belong to more than 1 category.

Patients who present with asymmetric gonads may be diagnosed with ovotesticular DSD or mixed gonadal dysgenesis (MGD). Ovotesticular DSD is defined as presence of both ovarian and testicular tissues in the same individual and may be classified as 46,XX DSD or 46,XY DSD, whereas MGD refers to individuals presenting with a differentiated testis on one side and a dysgenetic "streak" gonad on the other. ${ }^{2,3)}$ MGD, which is classified as a sex chromosome DSD, is the most complex type of DSD. It is associated with numerous sex chromosome abnormalities leading to abnormal gonadal development. ${ }^{4)}$

Variable clinical features frequently lead to confusion in diagnosis of ovotesticular DSD 
and MGD. Hormonal profiles, karyotypes, and an internal genital duct are not helpful in differential diagnosis. ${ }^{5)}$ Therefore, differential diagnosis of these conditions is problematic and is mainly based on pathological findings of the gonads. ${ }^{6}$ The differential diagnosis of ovotesticular DSD and MGD has important clinical implications for sex assignment, decisions regarding early gonadectomy in patients with MGD to prevent development of malignant germ cell tumors, and predictions of long-term outcomes.

Several retrospective studies have reported the clinical characteristics, sex of rearing, and long-term outcomes for a small number of children with ovotesticular DSD and MGD ${ }^{5,7-11)}$ The present study investigated the clinical features, karyotypes, sex of rearing, and pubertal outcomes of patients with ovotesticular DSD and MGD.

\section{Materials and methods}

\section{Subjects}

This study comprised 23 patients with DSD who presented with asymmetric gonads at the Department of Pediatrics at Asan Medical Center Children's Hospital in Seoul, Korea. The presenting features, endocrinological findings, karyotypes, presence of Müllerian duct remnants, pathological findings of the gonads, sex of rearing, and pubertal outcomes were reviewed retrospectively.

Patients with sex chromosome DSD whose diagnoses were not confirmed pathologically were excluded from this study. Sex assignment was based on integrative assessments of the external genitalia, presence of a uterus, functioning testicular tissues, hormonal profiles, and karyotypes and was performed using a multidisciplinary approach with informed consent from the parents of each patient.

\section{Methods}

External genitalia were rated using the external masculinization score (EMS). ${ }^{12)}$ A micropenis was defined as a stretched penile length less than $2.5 \mathrm{~cm}$ in a full-term neonate. ${ }^{13)}$ Internal genital organs were assessed by ultrasonography or magnetic resonance imaging.

A human chorionic gonadotropin (hCG) stimulation test was performed in 10 patients to evaluate Leydig cell function. Serum testosterone level was measured at baseline and on the fourth day after consecutive intramuscular hCG injections at a dose of 1,000 units/day for 3 days. The testosterone response to hCG was regarded as positive if the level increased to at least twice baseline or above the upper limit of the prepubertal testosterone level. $^{14)}$

Chromosomal analysis was performed in all subjects by examining metaphase $\mathrm{G}$ bands prepared from peripheral blood lymphocytes using conventional techniques. ${ }^{15)}$ Histopathological diagnosis of the gonads to differentiate ovotesticular DSD from MGD was based on resected or biopsied tissues.

\section{Results}

\section{Cytogenetic analysis and pathological diagnosis}

Gonadectomy or biopsy was performed at a median age of 2.9 years (range, 1 month-15.1 years). Subsequently, 14 patients were diagnosed with ovotesticular DSD, and 9 were diagnosed with MGD. The positions and histology of the gonads are summarized in Tables 1 and 2.

In the 14 patients with ovotesticular DSD, the most common karyotype was 46,XX (10 of 14,71.4\%), followed by 45,X/46,XY ( 3 of $14,21.4 \%$ ) and $46, X X / 46, X Y(1$ of $14,7.1 \%)$. A gonadal combination of testis and ovary was the most common finding ( 10 of $14,71.4 \%$ ), followed by bilateral ovotestes ( 2 of $14,14.3 \%$ ), ovary and ovotestis ( 1 of $14,7.1 \%$ ), and testis and ovotestis ( 1 of $14,7.1 \%)$.

In the 9 patients diagnosed with MGD, the most common karyotype was $45, \mathrm{X} / 46, \mathrm{XY}(6 / 9,66.7 \%)$. Other mosaicisms were identified in the other 3 patients $(33.3 \%): 45, \mathrm{X} / 46, \mathrm{X}, \operatorname{del}(\mathrm{Y})$ (q11.23), 45,X/46,X, add(Y)(p.11.3), and 45,X/47,XY,+del(Y) (q12).

\section{Clinical characteristics at presentation}

All 23 patients presented with ambiguous genitalia, such as a micropenis, cryptorchidism, hypospadias, or clitoromegaly, at a median age of 1 month (range, 1 day-1.6 years). Eleven of 14 patients with ovotesticular DSD (78.6\%) and all 9 patients with MGD (100\%) presented with asymmetric gonads. The appearance of the genitalia included prominent labia majora or absent scrotal rugae (13 of $23,56.5 \%$ ), hypospadias (15 of $23,65.2 \%$ ), clitoromegaly ( 8 of $23,34.8 \%$ ), cryptorchidism ( 5 of $23,21.7 \%$ ), and micropenis ( 4 of $23,17.4 \%$ ). The EMSs ranged between 2.5 and 11.5. None of the patients exhibited the stigmata of Turner syndrome. Müllerian duct remnants were identified in 10 of 14 patients with ovotesticular DSD (71.4\%) and in 5 of 9 patients with MGD (55.6\%).

Level of $17 a$-hydroxyprogesterone was measured in 16 subjects and was normal in all, excluding the possibility of congenital adrenal hyperplasia. The hCG stimulation test was performed in 8 subjects with ovotesticular DSD and in 2 subjects with MGD during the prepubertal period (range, 4-11 months). Seven of the 8 subjects $(87.5 \%)$ with ovotesticular DSD and both subjects (100\%) with MGD showed a positive response.

\section{Gender of rearing and clinical course}

Eight of the 14 patients (57.1\%) with ovotesticular DSD were assigned as male, and 7 of these patients (50\%) had preserved testis. The remaining 6 patients $(42.9 \%)$ were raised as female, and the ovaries were preserved in 3 of these 6 patients (50\%). Among the 8 male-assigned patients, unilateral gonadectomy 
was performed in 7 at a median age of 1.5 years (range, 4 months-15.1 years). In these 7 patients, the ovotestis or ovary was removed, whereas the testis was preserved to induce spontaneous puberty. Subject 3, a male-assigned patient with bilateral ovotestes in the scrotum, underwent bilateral gonadectomy at age 15.1 years due to spontaneous rupture of the left gonad. Of 6 female-assigned patients, 3 underwent bilateral or unilateral gonadectomy at a median age of 12 months (range, 1 month-9.2 years). Eight patients with ovotesticular DSD ( 5 males and 3 females) reached pubertal age during the study period, which was defined as $\geq 12$ years for males and $\geq 10$ years for females. Of these 8 patients, 6 with ovotesticular DSD (4 males and 2 females) showed spontaneous puberty (Table 3 ). The hCG stimulation test was performed in 3 of 4 male-assigned patients with spontaneous puberty, and all 3 patients were responsive. One female- and 3 male-assigned patients underwent unilateral gonadectomy at a median age of 2.4 years (range, 9 months-14 years). Subject 7, who underwent clitoroplasty at another hospital, was referred to our institute at the age of 9.1 years with clitoromegaly. The patient's Tanner stage was breast II and pubic hair II with serum luteinizing hormone and follicle-stimulating hormone levels of 6.0 and $5.0 \mathrm{mIU} /$
$\mathrm{mL}$, respectively (Table 3). As the patient was reared as a female, bilateral gonadectomy was performed at 9.2 years of age. Three patients (subjects 3,6, and 13) were treated with sex hormone replacement therapy. One male-assigned patient (subject 3 ) underwent bilateral gonadectomy due to spontaneous rupture of gonads at age 15.1 years; the patient was subsequently treated with testosterone enanthate. One female-assigned patient (subject 13) who underwent bilateral gonadectomy at the age of 1.3 years showed hypergonadotropic hypogonadism. This patient was treated with estrogen/progesterone replacement therapy starting at the age of 11.4 years. One male-assigned patient with ovotesticular DSD (subject 6) had sex identity problems and sex dysphoria at age 20 years. The patient changed his sex to female and subsequently underwent treatment with estrogen replacement therapy (Table 3, Fig. 1).

Seven of the 9 patients with MGD (77.8\%) were raised as males, whereas the remaining 2 patients were raised as females. Six of the male-assigned patients underwent a unilateral gonadectomy. The 2 female-assigned patients underwent a bilateral $(n=1)$ or unilateral $(n=1)$ gonadectomy to avoid virilization. Two patients with MGD reached pubertal age. Of these, puberty occurred spontaneously in one phenotypic

Table 1. Clinical and cytogenetic features of patients with ovotesticular disorder of sex development

\begin{tabular}{|c|c|c|c|c|c|c|c|c|}
\hline $\begin{array}{l}\text { Subject } \\
\text { No. }\end{array}$ & $\begin{array}{c}\text { Age at } \\
\text { presentation }\end{array}$ & $\begin{array}{l}\text { Sex of } \\
\text { rearing }\end{array}$ & Karyotype & Gonad, right/left & Position, right/left & $\begin{array}{l}\text { Müllerian duct } \\
\text { remnants }\end{array}$ & EMS & $\begin{array}{c}\text { Testosterone response to } \\
\text { hCG stimulation }\end{array}$ \\
\hline 1 & $1 \mathrm{mo}$ & $\mathrm{F}$ & $46, X X$ & Ovary/ovotestis & Abdomen/inguinal & Yes & 5 & ND \\
\hline 2 & $1 \mathrm{mo}$ & $\mathrm{F}$ & $46, X X$ & Testis/ovary & Inguinal/abdomen & No & 7.5 & Yes \\
\hline 3 & $1.6 \mathrm{yr}$ & M & $46, X X$ & Ovotestis/ovotestis & Scrotum/scrotum & No & 9 & ND \\
\hline 4 & 2 day & M & $46, X X$ & Testis/ovary & Scrotum/scrotum & Yes & 10 & Yes \\
\hline 5 & $1 \mathrm{mo}$ & M & $46, X X$ & Ovary/testis & Abdomen/scrotum & Yes & 8 & ND \\
\hline 6 & $1 \mathrm{mo}$ & M & $46, X X$ & Ovary/testis & Abdomen/scrotum & Yes & 9 & ND \\
\hline 7 & $1 \mathrm{mo}$ & $\mathrm{F}$ & $46, X X$ & Ovotestis/ovotestis & Inguinal/inguinal & No & 3 & ND \\
\hline 8 & $2 \mathrm{mo}$ & M & $46, X X$ & Ovary/testis & Abdomen/inguinal & Yes & 7.5 & Yes \\
\hline 9 & $1 \mathrm{mo}$ & $\mathrm{F}$ & $46, X X$ & Testis/ovary & Scrotum/abdomen & Yes & 7.5 & Yes \\
\hline 10 & $9 \mathrm{mo}$ & $\mathrm{F}$ & $46, X X$ & Testis/ovary & Labium/abdomen & Yes & 2.5 & No \\
\hline 11 & 1 day & M & $45, X[22] / 46, X Y[8]$ & Testis/ovary & Scrotum/inguinal & No & 8 & Yes \\
\hline 12 & $1 \mathrm{mo}$ & M & $45, X[11] / 46, X Y[19]$ & Testis/ovary & Scrotum/abdomen & Yes & 9 & Yes \\
\hline 13 & $12 \mathrm{mo}$ & $\mathrm{F}$ & $45, X[5] / 46, X Y[20]$ & Testis/ovotestis & Inguinal/scrotum & Yes & 3.5 & ND \\
\hline 14 & $1 \mathrm{mo}$ & M & $46, X X[39] / 46, X Y[11]$ & Testis/ovary & Scrotum/abdomen & Yes & 8 & Yes \\
\hline
\end{tabular}

EMS, external masculinization score; hCG, human chorionic gonadotropin; ND, not done.

Table 2. Clinical and cytogenetic features of patients with mixed gonadal dysgenesis

\begin{tabular}{|c|c|c|c|c|c|c|c|c|}
\hline $\begin{array}{l}\text { Subject } \\
\text { No. }\end{array}$ & $\begin{array}{c}\text { Age at } \\
\text { presentation }\end{array}$ & $\begin{array}{l}\text { Sex of } \\
\text { rearing }\end{array}$ & Karyotype & Gonad, right/left & Position, right/left & $\begin{array}{l}\text { Müllerian duct } \\
\text { remnants }\end{array}$ & EMS & $\begin{array}{l}\text { Testosterone } \\
\text { response to hCG } \\
\text { stimulation }\end{array}$ \\
\hline 15 & 1 month & $\mathrm{F}$ & $45, X[18] / 46, X Y[32]$ & Testis/dysgenetic gonad & Scrotum/abdomen & Yes & 2.5 & ND \\
\hline 16 & 1 month & M & $45, X[24] / 46, X Y[16]$ & Dysgenetic gonad/testis & Inguinal/scrotum & No & 8.5 & ND \\
\hline 17 & 1 month & M & $45, X[18] / 46, X Y[12]$ & Dysgenetic gonad/testis & Inguinal/scrotum & No & 6.5 & Yes \\
\hline 18 & 1 month & $\mathrm{F}$ & $45, X[25] / 46, X Y[15]$ & Dysgenetic gonad/testis & Abdomen/inguinal & Yes & 3 & ND \\
\hline 19 & 1 month & M & $45, X[36] / 46, X Y[4]$ & Dysgenetic gonad/testis & Abdomen/inguinal & Yes & 7.5 & Yes \\
\hline 20 & 1 month & M & $45, X[15] / 46, X Y[85]$ & Dysgenetic gonad/testis & Abdomen/scrotum & No & 8 & ND \\
\hline 21 & 1 month & M & $46, X, \operatorname{del}(Y)(q 11.23)[21] / 45, X[9]$ & Testis/dysgenetic gonad & Scrotum/abdomen & Yes & 10.5 & ND \\
\hline 22 & 2 months & M & $45, X[93] / 46, X, a d d(Y)(p .11 .3)[7]$ & Testis/dysgenetic gonad & Scrotum/abdomen & Yes & 8 & ND \\
\hline 23 & 4 months & M & $47, X Y,+\operatorname{del}(Y)(q 12)[43] / 45, X[7]$ & Dysgenetic gonad/testis & Inguinal/scrotum & No & 11.5 & ND \\
\hline
\end{tabular}

EMS, external masculinization score; hCG, human chorionic gonadotropin; ND, not done. 
Table 3. Endocrine characteristics of patients who reached pubertal age

\begin{tabular}{|c|c|c|c|c|c|c|c|c|c|c|c|c|}
\hline \multirow{2}{*}{$\begin{array}{l}\text { Subject } \\
\text { No. }\end{array}$} & \multirow{2}{*}{$\begin{array}{l}\text { Current } \\
\text { age (yr) }\end{array}$} & \multirow{2}{*}{$\begin{array}{l}\text { Sex of } \\
\text { rearing }\end{array}$} & \multirow{2}{*}{$\begin{array}{l}\text { MPH } \\
\text { SDS }\end{array}$} & \multirow{2}{*}{$\begin{array}{l}\text { Height } \\
\text { SDS }\end{array}$} & \multirow{2}{*}{$\begin{array}{c}\text { Weight } \\
\text { SDS }\end{array}$} & \multirow{2}{*}{$\begin{array}{c}\text { Age at } \\
\text { pubertal } \\
\text { onset (yr) }\end{array}$} & \multicolumn{4}{|c|}{ Basal hormone levels at pubertal onset } & \multirow[b]{2}{*}{ Gonadectomy } & \multirow{2}{*}{$\begin{array}{l}\text { Age at sex hormone } \\
\text { replacement } \\
\text { therapy (yr) }\end{array}$} \\
\hline & & & & & & & $\begin{array}{c}\mathrm{LH} \\
(\mathrm{mlU} / \mathrm{mL})\end{array}$ & $\begin{array}{c}\text { FSH } \\
(\mathrm{mlU} / \mathrm{mL})\end{array}$ & $\begin{array}{l}\text { Estradiol } \\
(\mathrm{pg} / \mathrm{mL})\end{array}$ & $\begin{array}{c}\text { Testosterone } \\
(\mathrm{ng} / \mathrm{mL})\end{array}$ & & \\
\hline 3 & 16.1 & M & NA & -0.05 & -0.73 & No & 28.1 & 42.1 & 21.8 & 2.0 & Bilateral & 15.1 \\
\hline 4 & 14.0 & M & 0.45 & -0.28 & -0.95 & 12.7 & 10.4 & 11.0 & ND & 4.3 & Left & $\mathrm{ND}^{+}$ \\
\hline $6^{*}$ & 22.9 & M & NA & -0.69 & 0.16 & No & 22.0 & 25.8 & 4.0 & 0.92 & Right & $22.9^{\dagger}$ \\
\hline 7 & 11.1 & $\mathrm{~F}$ & -0.11 & 0.91 & 0.55 & 9.1 & 6.0 & 5.0 & 24.9 & ND & Bilateral & $\mathrm{ND}^{\dagger}$ \\
\hline 10 & 12.7 & $\mathrm{~F}$ & 0.98 & 0.64 & 1.06 & 12.1 & 3.2 & 7.0 & 4.0 & 0.24 & Right & $\mathrm{ND}^{\dagger}$ \\
\hline 11 & 18.6 & M & -0.26 & -2.57 & 0.26 & 12.8 & 3.5 & 6.5 & 12.5 & 2.6 & Left & $\mathrm{ND}^{\dagger}$ \\
\hline 12 & 16.6 & M & -0.91 & -1.62 & -1.14 & 11.0 & 2.3 & 12.0 & ND & 0.19 & Left & $\mathrm{ND}^{\dagger}$ \\
\hline 13 & 13.0 & F & NA & -1.15 & 1.74 & No & 7.7 & 48.8 & 7.7 & ND & Bilateral & 11.4 \\
\hline 15 & 21.2 & F & NA & -2.09 & -2.53 & No & 6.9 & 60.5 & 12.3 & 0.04 & Right & 11.5 \\
\hline 19 & 13.6 & $M$ & -0.54 & -2.10 & 0.96 & 11.8 & 1.6 & 7.1 & ND & 1.2 & Right & $\mathrm{ND}^{\dagger}$ \\
\hline
\end{tabular}

$\mathrm{MPH}$, midparental height; SDS, standard deviation score; LH, luteinizing hormone; FSH, follicle-stimulating hormone; NA, not available; $\mathrm{ND}$, not done.

${ }^{*}$ Changed sex to female at age 20 years. ${ }^{\dagger}$ Patients who showed spontaneous puberty.

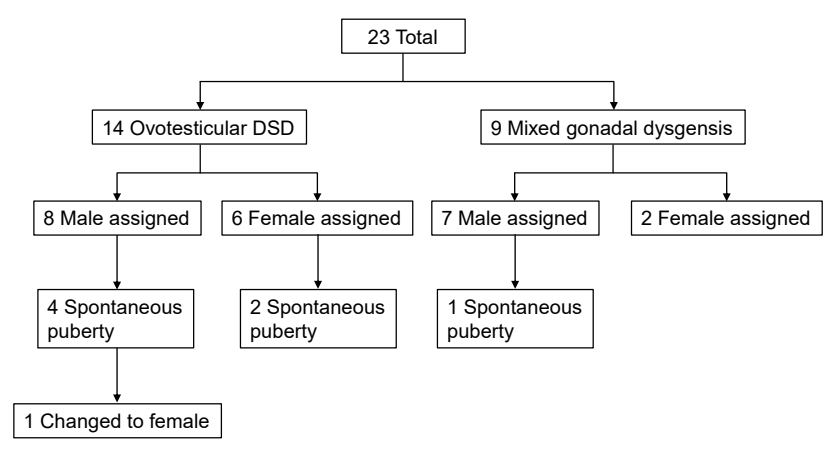

Fig. 1. Sex of rearing and pubertal outcomes of patients with ovotesticular disorder of sex development (DSD) and mixed gonadal dysgenesis.

male at the age of 11.8 years (subject 19) with MGD, and sex hormone replacement was not necessary during the follow-up period (Table 3, Fig. 1). The remaining one female with MGD (subject 15) who underwent a right gonadectomy at the age of 1.2 years showed hypergonadotropic hypogonadism caused by a contralateral dysgenetic gonad and was treated with estrogen replacement therapy starting at 11.5 years of age.

\section{Discussion}

This study demonstrated that patients with ovotesticular DSD and MGD present a wide clinical and cytogenetic spectrum encompassing phenotypic females, with or without virilization, and phenotypic males, presenting with a micropenis, hypospadias, or cryptorchidism. It is difficult to differentiate ovotesticular DSD from MGD based on clinical features, hormonal profiles, and cytogenetic analysis. The nature of the internal and external genitalia does not form the basis for a differential diagnosis between ovotesticular DSD and MGD. In our study, remnants of the Müllerian duct structure, a rudimentary uterus, and fallopian tubes were identified in 10 of $14(71.4 \%)$ ovotesticular DSD patients and in 5 of $9(55.6 \%)$
MGD patients. Therefore, histological findings of gonads are critical for differential diagnosis of ovotesticular DSD and MGD. ${ }^{5)}$

Various types of chromosomal abnormalities have been described in patients with ovotesticular DSD or MGD. The most frequent karyotype of ovotesticular DSD is 46, XX, followed by 46,XX/XY; 46,XY; and 45,X/46,XY. ${ }^{16)}$ Patients with MGD also have heterogeneous karyotypes characterized by 45,X/46,XY; 45,X/47,XXY; or rarely 46,XY. ${ }^{17-19)}$ However, karyotype alone cannot differentiate ovotesticular DSD from MGD in every case. The 45,X/46,XY karyotype can be identified both in ovotesticular DSD patients and MGD patients. In the present study, 3 patients with ovotesticular DSD and 6 patients with MGD harbored the 45,X/46,XY karyotype. The $45, \mathrm{X} / 46, \mathrm{XY}$ mosaicism is an important component of sex chromosome DSD, which is characterized by a wide phenotypic spectrum, ${ }^{3,20,21)}$ resulting in challenging diagnosis. In addition, the 46,XY karyotype is found in both ovotesticular DSD and MGD patients, ${ }^{10,18,19,22)}$ which emphasizes the need for histological analysis for confirmatory diagnosis rather than peripheral blood karyotypes.

Clinically, the presence of functional testicular tissue can be determined with the hCG stimulation test in adults. There are limited published data on hCG stimulation tests in patients with ovotesticular DSD. ${ }^{13,16)}$ Serum testosterone level before and after stimulation has been reported to be variable and dependent on patient age and pubertal stage. ${ }^{10)}$ In our study, 6 of 9 patients $(66.7 \%)$ who were responsive to hCG stimulation were raised as males. The other 3 patients were raised as females upon consideration of external and internal genitalia or parent predilection. These patients should be followed up for evaluation of gender identity.

Puberty has been reported to occur spontaneously in patients with MGD or ovotesticular DSD. ${ }^{3,10)}$ However, in male-assigned patients with ovotesticular DSD, testicular tissues become dysgenetic over time, and germ cells begin to disappear with advanced age, while ovaries remain functional, ${ }^{7,13}$ requiring testosterone injections in later life. ${ }^{10)}$ In female-assigned patients 
with ovotesticular DSD, menstruation is expected in 50\% of cases with well-developed ovarian tissue. ${ }^{23)}$ Thus, patients who show spontaneous puberty should be followed up for progression of puberty.

There are many issues to be considered when assessing gender: gonadal function, phenotype, internal genitalia, potential of fertility and sexuality, risk of gonadal malignancy, and prenatal brain virilization. ${ }^{24,25)}$ In patients with ovotesticular DSD, the frequency of male-assigned patients in South Africa and China was $62.5 \%$ and $93.8 \%$, respectively. ${ }^{10,22)}$ In contrast, the frequency of male-assigned patients with MGD in Turkey and the USA was $25 \%$ and $55 \%$, respectively. ${ }^{3,26)}$ Sex assignment was based on integrative assessments of Prader grade, nature and function of gonads, presence of Mullerian ducts, karyotypes, and psychological characteristics. ${ }^{3,22)}$ All subjects were assigned male or female sex after counseling by a multidisciplinary team including a pediatric endocrinologist, pediatric urologist, gynecologist, medical geneticist, clinical psychiatrist, and social worker. $^{10)}$

Gender identity can be predicted by several factors, such as presence of a Y chromosome, degree and duration of pre- and postnatal androgen exposure, and phenotypic presentation of external genitalia. However, there are few reports on long-term outcomes in patients with ovotesticular DSD and MGD, ${ }^{8,9)}$ and the frequency of gender dysphoria in ovotesticular DSD and MGD remains unknown. Therefore, sex assignment should be continued after completion of the diagnostic process in the light of clinical, endocrinological, genetic, and psychiatric aspects with full informed consent from the parents to recognize and manage sex dysphoria at a young age and to help prevent or reduce psychological complications at the onset of puberty. ${ }^{3,10,27)}$ In the present study, only 1 patient (subject 6) with ovotesticular DSD showed sex dysphoria and reassigned as a female. This patient underwent a unilateral gonadectomy at the age of 2.9 years and was lost to follow up until the age of 20 years. Previously, 3 female-assigned patients with ovotesticular DSD reassigned as males, ${ }^{9)}$ and a patient with MGD who was raised as a female after an early gonadectomy reassigned as male during adolescence. ${ }^{11)}$

Sex identity, pubertal progression, and potential gonadal tumor occurrence need to be monitored in patients with ovotesticular DSD and MGD. The risk of malignancy in patients with ovotesticular DSD is low $(2.6 \%-4.6 \%)$, especially in the absence of a Y chromosome. ${ }^{16)}$ In contrast, MGD patients harboring $\mathrm{Y}$ chromosome material are thought to have a significant risk of malignancy, ranging from $25 \%$ to $30 \%{ }^{28-}$ 30) Therefore, bilateral gonadectomy should be performed in female-assigned patients with MGD before the patient reaches puberty, not only to prevent development of malignant tumors, but also to avoid virilization. Although gonadal tumors were not detected during follow-up in our study, long-term follow-up is needed to screen gonadal malignancies, especially in patients with dysgenic gonads, such as subject 15 .

There are a few limitations in this study. As this was a retrospective study, there are issues with data integrity, such as missing data, and the follow-up period varied among the patients. The hCG stimulation test was performed only in a small number of patients, and the age at testing differed among patients because the patients were collected over a long duration. In addition, histological findings were analyzed by retrospective chart review and not reviewed by an expert.

In conclusion, this study demonstrated that ovotesticular DSD and MGD manifest a wide spectrum of clinical features and karyotypes. Long-term follow-up of such patients into adulthood will provide important information on comorbidities such as risk of gonadal tumors, urological complications, and neuropsychological outcomes.

\section{Conflict of interest}

No potential conflict of interest relevant to this article was reported.

\section{Acknowledgments}

This study was supported by the Basic Science Research Program through the National Research Foundation of Korea (NRF) funded by the Ministry of Education (2017R1D1A1B03029638).

\section{Ethical statement}

This study was approved by the Institutional Review Board of Asan Medical Center, Seoul, Korea (IRB number: 20190160). Informed consent was obtained from the parents of each patient.

\section{References}

1. Lee PA, Houk CP, Ahmed SF, Hughes IA; International Consensus Conference on Intersex organized by the Lawson Wilkins Pediatric Endocrine Society and the European Society for Paediatric Endocrinology. Consensus statement on management of intersex disorders. International Consensus Conference on Intersex. Pediatrics 2006;118:e488-500.

2. Krstić ZD, Smoljanić Z, Vukanić D, Varinac D, Janjić G. True hermaphroditism: 10 years' experience. Pediatr Surg Int 2000;16:580-3.

3. Ocal G, Berberoğlu M, Sıklar Z, Ruhi HI, Tükün A, Camtosun E, et al. The clinical and genetic heterogeneity of mixed gonadal dysgenesis: does "disorders of sexual development (DSD)" classification based on new Chicago consensus cover all sex chromosome DSD? Eur J Pediatr 2012;171:1497-502.

4. Barthold JS. Disorders of sex differentiation: a pediatric urologist's perspective of new terminology and recommendations. J Urol 2011;185:393-400.

5. Kim KR, Kwon Y, Joung JY, Kim KS, Ayala AG, Ro JY. True hermaphroditism and mixed gonadal dysgenesis in young 
children: a clinicopathologic study of 10 cases. Mod Pathol 2002;15:1013-9.

6. Wiersma R. True hermaphroditism in southern Africa: the clinical picture. Pediatr Surg Int 2004;20:363-8.

7. Verkauskas G, Jaubert F, Lortat-Jacob S, Malan V, Thibaud E, Nihoul-Fékété C. The long-term followup of 33 cases of true hermaphroditism: a 40-year experience with conservative gonadal surgery. J Urol 2007;177:726-31.

8. Matsui F, Shimada K, Matsumoto F, Itesako T, Nara K, Ida $\mathrm{S}$, et al. Long-term outcome of ovotesticular disorder of sex development: a single center experience. Int J Urol 2011;18:231-6

9. Sircili MH, Denes FT, Costa EM, Machado MG, Inacio M, Silva RB, et al. Long-term followup of a large cohort of patients with ovotesticular disorder of sex development. J Urol 2014;191(5 Suppl):1532-6.

10. Ganie Y, Aldous C, Balakrishna Y, Wiersma R. The Spectrum of Ovotesticular disorders of sex development in South Africa: a single-centre experience. Horm Res Paediatr 2017;87:307-14.

11. Ocal G, Berberoğlu M, Siklar Z, Bilir P. Gender dysphoria and gender change in an adolescent with 45,X/46,XY mixed gonadal dysgenesis. Exp Clin Endocrinol Diabetes 2009;117:301-4.

12. Ahmed SF, Khwaja O, Hughes IA. The role of a clinical score in the assessment of ambiguous genitalia. BJU Int 2000;85:120-4.

13. Aaronson IA. True hermaphroditism. A review of 41 cases with observations on testicular histology and function. Br J Urol 1985;57:775-9.

14. Ahmed SF, Achermann JC, Arlt W, Balen A, Conway G, Edwards Z, et al. Society for Endocrinology UK guidance on the initial evaluation of an infant or an adolescent with a suspected disorder of sex development (Revised 2015). Clin Endocrinol (Oxf) 2016;84:771-88.

15. Takahashi I, Miyamoto J, Hasegawa Y. Limitations of G-banding karyotype analysis with peripheral lymphocytes in diagnosing mixed gonadal dysgenesis. Clin Pediatr Endocrinol 2006;15:109-15.

16. Hadjiathanasiou CG, Brauner R, Lortat-Jacob S, Nivot S, Jaubert F, Fellous M, et al. True hermaphroditism: genetic variants and clinical management. J Pediatr 1994;125(5 Pt 1):738-44.

17. Méndez JP, Ulloa-Aguirre A, Kofman-Alfaro S, Mutchinick O, Fernández-del-Castillo C, Reyes E, et al. Mixed gonadal dysgenesis: clinical, cytogenetic, endocrinological, and histopathological findings in 16 patients. Am J Med Genet 1993;46:263-7.

18. Nishina-Uchida N, Fukuzawa R, Hasegawa Y, Morison IM. Identification of $\mathrm{X}$ monosomy cells from a gonad of mixed gonadal dysgenesis with a 46,XY karyotype: case report. Medicine (Baltimore) 2015;94:e720.

19. Klee P, Béna F, Birraux J, Dahoun S, Dirlewanger M, Girardin C, et al. A novel SRY mutation leads to asymmetric SOX9 activation and is responsible for mixed 46,XY gonadal dysgenesis. Horm Res Paediatr 2012;78:188-92.

20. Layman LC, Tho SP, Clark AD, Kulharya A, McDonough PG. Phenotypic spectrum of 45,X/46,XY males with a ring $Y$ chromosome and bilaterally descended testes. Fertil Steril 2009;91:791-7.

21. Tosson H Rose SR, Gartner LA. Children with 45,X/46,XY karyotype from birth to adult height. Horm Res Paediatr 2010;74:190-200.

22. Mao Y, Chen S, Wang R, Wang X, Qin D, Tang Y. Evaluation and treatment for ovotesticular disorder of sex development (OT-DSD) - experience based on a Chinese series. BMC Urol 2017;17:21.

23. van Niekerk WA, Retief AE. The gonads of human true hermaphrodites. Hum Genet 1981;58:117-22.

24. Birnbacher R, Marberger M, Weissenbacher G, Schober E, Frisch H. Gender identity reversal in an adolescent with mixed gonadal dysgenesis. J Pediatr Endocrinol Metab 1999;12:687-90.

25. Cohen-Kettenis PT. Psychosocial and psychosexual aspects of disorders of sex development. Best Pract Res Clin Endocrinol Metab 2010;24:325-34.

26. Reiner WG. Gender identity and sex-of-rearing in children with disorders of sexual differentiation. J Pediatr Endocrinol Metab 2005;18:549-53.

27. Cools M, Nordenström A, Robeva R, Hall J, Westerveld P, Flück C, et al. Caring for individuals with a difference of sex development (DSD): a consensus statement. Nat Rev Endocrinol 2018;14:415-29.

28. Krob G, Braun A, Kuhnle U. True hermaphroditism: geographical distribution, clinical findings, chromosomes and gonadal histology. Eur J Pediatr 1994;153:2-10.

29. Sarafoglou K, Ostrer H. Clinical review 111: familial sex reversal: a review. J Clin Endocrinol Metab 2000;85:483-93.

30. Cools M, Drop SL, Wolffenbuttel KP, Oosterhuis JW, Looijenga LH. Germ cell tumors in the intersex gonad: old paths, new directions, moving frontiers. Endocr Rev 2006;27:468-84. 